\title{
Human herpes virus type 6 (HHV-6) and its in vitro effect on human immunodeficiency virus (HIV)
}

\author{
G R PIETROBONI, G B HARNETT, T J FARR, M R BUCENS \\ From the Virus Laboratory, Combined Microbiology Service, Queen Elizabeth II Medical Centre, Nedlands, \\ Western Australia
}

SUMMARY Human herpes virus type 6(HHV-6) was isolated from the peripheral blood lymphocytes of a patient infected with human immunodeficiency virus (HIV). Antibodies to this herpes virus were found to be widespread among adults and children in Western Australia. Co-infection studies indicated that HIV replication was inhibited by the presence of HHV-6.

Reports of a new herpes virus isolated from human lymphocyte cultures were first documented by workers at the National Cancer Institute. ${ }^{12}$ In accordance with herpes virus classification, the virus has since been designated human herpes virus-6 (HHV-6). ${ }^{3}$

Preliminary studies suggested a low prevalence of HHV-6 antibodies in the general population,' but more recent studies in the United Kingdom and West Germany indicate that such antibodies are common in the adult population..$^{46}$

This report describes the isolation of HHV-6 during routine culture of peripheral blood mononuclear cells from a patient seropositive for human immunodeficiency virus (HIV). Investigations indicating a high prevalence of antibodies to HHV-6 in adults and young children in Western Australia, and evidence that HIV growth is inhibited in the presence of HHV-6 in lymphocyte cultures are also presented.

\section{Material and methods}

A 22 year old man was first diagnosed as having HIV infection in April 1987. He was a homosexual and an intravenous drug abuser. The first specimen of blood for HIV culture was collected on October 27, with subsequent specimens taken on 7 and 25 of November.

Anticoagulated blood from the patient was separated on Ficoll-Paque (Pharmacia, Uppsala, Sweden) and $10^{7}$ lymphocytes were co-cultivated with $5 \times 10^{6}$ lymphocytes from anti-HIV negative blood donors. Donor lymphocytes were stimulated with phytohaemagglutinin (PHA) (Pharmacia, Uppsala, Sweden) at the dilution recommended by the manufacturer, for 48 hours preceding co-cultivation. Cells were cultured in $15 \mathrm{ml}$ RPMI 1640 growth medium (RPMI

Accepted for publication 11 July 1988
1640 (CSL, Melbourne, Australia) with $20 \%$ fetal calf serum (Flow Laboratories, North Ryde, New South Wales, Australia), $0.2 \%$ sodium bicarbonate, $3 \mathrm{mM}$ hydrochloric acid, human interleukin $2(2 \mathrm{U} / \mathrm{ml})$ (Collaborative Research Inc, Bedford, Massachusetts, USA), diethylaminoethyl-dextran $(1 \mathrm{mg} / 100 \mathrm{ml})$ (Pharmacia, Uppsala, Sweden), penicillin $(100 \mathrm{U} / \mathrm{ml})$, streptomycin $(100 \mu \mathrm{g} / \mathrm{ml})$, and neomycin $(35 \mu \mathrm{g} / \mathrm{ml}))$.

Cell-free culture fluids from infected lymphocyte 8 cultures were placed on formvar/carbon-coated grids, stained with $4 \%$ sodium silicotungstate, and examinedo by electron microscopy.

A monoclonal antibody to the viral capsid antigen of Epstein-Barr virus (EBV) was kindly donated by Dr D Moss, Queensland Institute of Medical Research, Australia. Monoclonal antibodies to herpes simplex virus (HSV) types 1 and 2, cytomegalovirus (CMV), and varicella zoster virus (VZV), were produced in our own laboratory. They had shown reactivity against many different isolates of the specific viruses.

A DNA extract from lymphocytes infected with virus $^{7}$ was sent for characterisation to $\mathrm{Dr} \mathbf{R}$ Honess, National Institute of Medical Research, London.

Cells from uninfected or HHV-6 infected lymphocyte cultures were washed, air dried on teflon coated glass slides, and fixed in $100 \%$ acetone for 10 minutes at room temperature. Slides were stored over liquid nitrogen until required.

Slides were pre-treated with a 1 in 5 dilution of normal rabbit serum for $\mathbf{4 5}$ minutes to block any Fc receptors expressed by cells infected with herpes viruses. ${ }^{8}$ Test sera were absorbed with a cell lysate of the human T-cell line HUT-78 to remove any anticellular activity, and the final 1 in 10 serum dilutions were incubated on the HHV-6 slides in a moist environment for 45 minutes at $35^{\circ} \mathrm{C}$. A selection of sera were also tested on uninfected lymphocyte slides. After two five minute washes in phosphate 
buffered saline ( $\mathrm{pH} 7 \cdot 3)$ goat anti-human IgG fluorescein-conjugate (Tago, Burlingame, California, USA) was applied to the slides which were incubated as before. After a final washing cycle slides were examined under an ultraviolet microscope (Photomicroscope, Zeiss, Oberkochen, West Germany) with incident light illumination.

Positive and control human serum pools were made from anti-HIV positive and negative specimens, respectively. Selected sera containing anti-HIV but not anti-HHV-6 were used to identify HIV in the presence of HHV-6. Sera or serum pools were absorbed with a HUT-78 lysate and then inactivated at $58^{\circ} \mathrm{C}$ for 30 minutes. Cells from lymphocyte cultures were fixed on to glass slides as previously described and incubated with the treated serum pools, used at pre-determined dilutions, in a moist environment for $\mathbf{4 5}$ minutes at $35^{\circ} \mathrm{C}$. The remaining wash and conjugate steps were as for anti-HHV-6 detection.

Some cell-free culture fluids were tested with a commercial HIV antigen detection assay (Vironostika HIV, Organon Teknika BV, Boxtel, Holland).

Antibody studies were performed on a random selection of samples from healthy blood donors, infants admitted to hospital for various disorders, HIV seropositive patients, and sera received at the laboratory for routine virus serology tests.

Plastic shell phials were seeded with $2 \times 10^{6}$ washed, PHA-stimulated peripheral blood lymphocytes in RPMI 1640 growth medium. Serial dilutions of cellfree culture fluids containing HHV-6 or HIV (ARV-2, kindly donated by $D$ Cooper with permission from JA Levy, Cancer Research Institute, California) were added to the shell phials, which were then centrifuged at $3000 \mathrm{rpm}$ for 60 minutes at $35^{\circ} \mathrm{C}$. Centrifugation of the virus on to cell monolayers has been reported to enhance infection of cells, ${ }^{9}$ and this occurs in the case of in vitro HIV infection of lymphocyte cultures (GR Pietroboni, unpublished observations). Appropriate controls were included. Cultures were incubated at $37^{\circ} \mathrm{C}$ in a $10 \%$ carbon dioxide environment, with $50 \%$ medium changes every three to four days. After 14 days cells were tested by immunofluorescence assay (IFA) for HHV-6 and HIV.

\section{Results}

An unusual immunofluorescence assay staining reaction was noticed while monitoring for HIV antigen expression during routine culture of human peripheral blood lymphocytes from an HIV seropositive patient. Many grossly enlarged cells gave positive reactions with the anti-HIV positive serum pool and stronger immunofluorescence with the control serum pool. The reactivity with the HIV positive serum pool progressively diminished, and by the 14th day of culture, was negative. The positive reaction with the control serum pool continued. It was subsequently found that the anti-HIV positive serum pool had negligible HHV-6 reactivity at the working dilution. HIV antigen was detected by enzyme immunoassay in cell-free culture fluid at days 6 and 14 but not at day 36. Donor lymphocytes gave negative immunofluorescence assay results with both serum pools and so were excluded as the source of virus infection.

Microscopic examination of the cell culture showed large balloon-like refractile cells but syncytia were not observed. Electron microscopic examination of the cell culture fluid showed particles with typical herpes virus morphology. Immunofluorescence assay studies on infected cells using monoclonal antibodies directed against HSV 1, HSV 2, CMV, VZV, and EBV, gave negative results. Analysis of the DNA extract from infected lymphocytes showed a Smal map very similar to the prototype HHV-6 strain. The DNA also hybridised strongly with the HHV-6 Smal probe (pSD2) which has been shown to be unique to HHV6. ${ }^{10}$

The two subsequent lymphocyte specimens received from the same patient failed to show evidence of HHV-6 infection, but HIV was successfully cultured from both specimens. Serum collected 12 months before isolation of HHV-6 had an anti-HHV-6 immunofluorescence assay titre of $1 / 320$, and similar titres were obtained for sera collected immediately before and after isolation of herpes virus.

Propagation of the herpes virus was continued by infection of two to three days to PHA-stimulated peripheral blood lymphocytes with culture supernatants. HHV-6 did not immortalise the infected cells.

In co-infection studies the presence of HIV had no effect on the titre of HHV-6 in lymphocytes, but HIV could only be detected in lymphocytes infected with an HHV-6 inoculum less than the 1 TCID $_{\text {so }}$ (table 1).

A random selection of sera from normal blood donors showed antibodies to HHV-6 in 57 of the 58 $(98 \%)$ sera tested. Of the 56 anti-HIV positive sera tested, $55(98 \%)$ had antibodies to HHV-6. Results of antibody studies for 338 sera arranged in age groups

Table 1 Inhibition of HIV replication in peripheral blood lymphocytes by $\mathrm{HHV}-6$

\begin{tabular}{|c|c|c|c|c|c|c|}
\hline & \multirow{2}{*}{$\begin{array}{l}\text { HIV inoculum } \\
\left(T C I D_{s o}\right)\end{array}$} & \multicolumn{5}{|c|}{$H H V-6$ inoculum $\left(T C I D_{50}\right)$} \\
\hline & & 100 & 10 & $1 \cdot 0$ & $0 \cdot 1$ & 0 \\
\hline \multirow{3}{*}{ HIV IFA } & 10 & $-*$ & - & - & + & + \\
\hline & 1 & - & - & - & + & + \\
\hline & 0 & - & - & - & - & - \\
\hline \multirow{3}{*}{ HHV-6 IFA } & 10 & + & + & + & - & - \\
\hline & 1 & + & + & + & - & - \\
\hline & 0 & + & + & + & - & - \\
\hline
\end{tabular}

+ and - indicate positive or negative IFA, respectively, after cultivation of lymphocytes for 14 days. 
Table 2 Age group distribution of antibody to HHV-6 in 338 patients

\begin{tabular}{llll}
\hline $\begin{array}{l}\text { Age } \\
\text { (months) }\end{array}$ & $\begin{array}{l}\text { HHV-6* } \\
\text { seropositive }\end{array}$ & $\begin{array}{l}\text { Total No } \\
\text { tested }\end{array}$ & $\begin{array}{l}\text { Percentage } \\
\text { seropositive }\end{array}$ \\
\hline$<1$ & 26 & 28 & 93 \\
1 & 12 & 15 & 80 \\
$2-4$ & 22 & 31 & 71 \\
$5-7$ & 15 & 23 & 65 \\
$8-10$ & 19 & 27 & 70 \\
$11-15$ & 30 & 37 & 81 \\
$16-24$ & 27 & 29 & 93 \\
$>24 \dagger$ & 183 & 194 & 94 \\
\hline
\end{tabular}

*Very weak positive or equivocal results were scored as negative. †Ages range from 25 months to 70 years.

are shown in table 2. By the age of 2 years, more than $90 \%$ of children had antibody to HHV-6. This rate may be an underestimate as weakly positive, equivocal results were scored negative. An alternate assay is required to elucidate this point.

\section{Discussion}

The presence of HHV-6 in the peripheral blood lymphocytes of an HIV positive patient was detected due to an unexpected immunofiuorescence assay reaction with an anti-HIV negative serum pool. Many laboratories use the reverse transcriptase assay to monitor cultures for retrovirus infection, and without microscopic examination of the culture this herpes virus would not have been detected. Analysis of the herpes virus DNA confirmed that the infected lymphocytes contained a high concentration of a genome very closely related to other isolates of HHV-6 and showing only very minor variations.

The results of co-infection studies indicate that HHV-6 replication can inhibit the growth of HIV in lymphocytes and produce a false negative HIV culture result. The nature of the inhibition remains undetermined but may simply be due to rapid destruction of HIV susceptible cells by HHV-6. Since the original isolation, control lymphocyte cultures from 22 blood donors have yielded one HHV-6 isolate, and a further isolate has been made from the lymphocytes of an HIV seropositive patient.

The serological results show that exposure to HHV-6 is widespread in Western Australia. More than $90 \%$ of the population represented in our study had been exposed to the virus by the age of 2 years. The decline in seropositivity to only $65 \%$ at 5 to 7 months is consistent with rapid acquisition of infection after loss of maternal antibody. The apparent variations in reported prevalence ${ }^{14-6}$ may be due in part to immunofluorescence assay techniques differing in initial serum dilution and absorbing protocols. Recently some DNA homology between CMV and HHV-6 has been reported, ${ }^{10}$ but it is not yet clear whether these or other herpes viruses share common antigens with HHV-6 which may reduce the specificity of the immunofluorescence assay test.

The widespread prevalence of antibodies to HHV-6 in infants suggests efficient congenital or early horizontal transmission of the virus. Our group has recently reported the isolation of HHV-6 from the saliva of healthy adults, ${ }^{11}$ which suggests a ready means for horizontal transmission, although our data do not exclude congenital transmission. While the in vivo effect of HHV-6 on HIV is unknown, the presence of HHV-6 in saliva and its inhibition of HIV in vitro may have led to the underestimation of the amount of HIV in saliva and its possible role as a vehicle for HIV transmission. Further studies relating to HHV-6 pathogenesis and its inhibitory effect on HIV are in progress.

The expert assistance of $R$ Honess for DNA analyses and $\mathbf{N}$ Sambell for DNA extraction is gratefully acknowledged. We also thank D Bockman for access to his patient.

This work was supported in part by a Commonwealth AIDS Research Grant through the NHMRC Special Unit for AIDS Virology.

\section{References}

1 Salahuddin SZ, Ablashi DV, Markham PD, et al. Isolation of a new virus, HBLV, in patients with lymphoproliferative disorders. Science 1986;234:596-601.

2 Josephs SF, Salahuddin SZ, Ablashi DV, Schachter F, Wong Staal F, Gallo RC. Genomic analysis of the human B-lymphotropic virus (HBLV). Science 1986;234:601-3.

3 Ablashi DV, Salahuddin SZ, Josephs SF, et al. HBLV (or HHV-6) in human cell lines. Nature 1987;329:207.

4 Tedder RS, Briggs M, Cameron CH, Honess R, Robertson D, Whittle $H$. A novel lymphotropic herpes virus. Lancet 1987;if:390-2.

5 Krueger GRF, Ablashi DV. Human B-lymphotropic virus in Germany. Lancet 1987;it:694.

6 Briggs M, Fox J, Tedder RS. Age prevalence of antibody to human herpes virus 6. Lancet 1988;i:1058-9.

7 Davis LG, Dibner MD, Battey JF. Preparation of DNA from eukaryotic cells: general method. In: Basic methods in molecular biology. New York: Elsevier, 1986:44-46.

8 Kerbel RS. Herpes virus induction of Fc receptors. Nature 1976;263:192.

9 Osborn JE, Walker DL. Enhancement of murine cytomegalovirus in vitro by centrifugal inoculation. $J$ Virol 1968;2:853-8.

10 Efstathiou S, Gompels UA, Craxton MA, Honess RW, Ward K. DNA homology between a novel human herpes virus (HHV-6) and human cytomegalovirus. Lancet 1988;i:63-4.

11 Pietroboni GR, Harnett GB, Bucens MR, Honess RW. Antibody to human herpesvirus 6 in saliva. Lancet 1988;i:1059.

Requests for reprints to: Miss G R Pietroboni, Virus Laboratory, Combined Microbiology Service, Queen Elizabeth II Medical Centre, Nedlands, Western Australia, 6009. 